\title{
Smart Growth and Urban Development
}

\author{
Xing Ding ${ }^{\mathrm{a},{ }^{*}}$ \\ School of North China Electric Power University, Baoding 071003, China \\ adingxing2014@126.com
}

Keywords: Smart Growth, Principal Component Analysis, BP neural network.

\begin{abstract}
Smart Growth theory, Originated in the 1990's, advocate a people-oriented, healthy and harmonious development concept, and it has an increasingly important position in urban planning. In order to help implement the smart growth theories into city design around the world, we have chosen Bendigo from Australia and Galway from Ireland to measure the success of the selected cities in the current development plan and give our suggestions in the future. First, taking the ten principles of smart growth into account, we select ten indicators (natural population growth rate, the percentage of undergraduate students aged fifteen and over, etc) and by using Principal Component Analysis, we get the main factors affecting the urban smart growth. Then, taking the above analysis of the main factors and the two cities of their geographical location and other features into account, We selected different indicators for each city, use BP neural network to predict the change of other indicators in the next 20 years and test the correctness of the parameters. After that, we design the development indicators of the two cities in the next 20 years, provide our corresponding suggestions.
\end{abstract}

\section{Introduction}

Looking back through the development process of the cities around the world, The United States experienced a "Urban Sprawl" of land use, and after that New Urbanism and Smart Growth were widely accepted. They both advocated a better use of existing infrastructure, focusing on environmental protection, resource saving and healthy financial position and promoted a balanced development of society.[1] While Britain advocated building 'Sustainable Communities' .They proposed a national program titled "build a architectural symbol for the future " in 2004 to develop cities more scientifically. [2]Smart Growth theory, Originated in the 1990's, advocate a people-oriented, healthy and harmonious development concept, and it has an increasingly important position in urban planning.

\section{BP Neural Network}

BP neural network is a kind of multilayer feed-forward neural network. The main features of the network are signal propagates forward and errors propagate reversely. The input signal is processed from the input layer to the hidden layer and finally arrives to output layer when it propagates forward. The state of each neuron in each layer can only influence that at the next layer. If the output layer cannot get the expected output, the signal turns to back propagation and adjusts network weights and thresholds according to the prediction error. By this process, BP neural network's prediction output can approach the expected output constantly.

The picture below is the topological structure of BP neural network. 


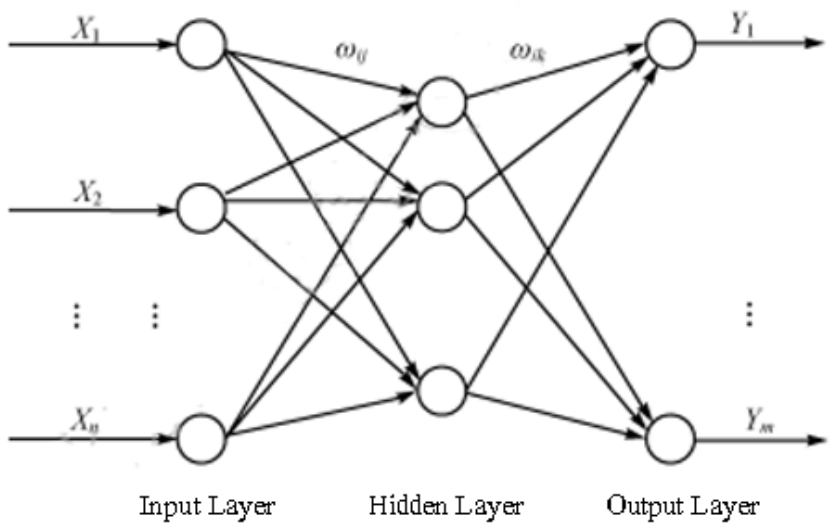

Figure 1: The topological structure of BP neural network. [3]

As shown in figure, $X_{1}, X_{2}, \cdots X_{\mathrm{n}}$ are the input of the BP neural network, $Y_{1}, Y_{2}, \cdots Y_{\mathrm{m}}$ are the prediction output, $i j$ and $j k$ are the network weights of BP neural network. We can see from the figure, BP neural network can be regarded as a nonlinear function, input and output of the network are independent variables and dependent variables. When the input node number is $n$, the output number is $m$, BP neural network expresses the mapping relations from the $\mathrm{n}$ independent variables to $\mathrm{m}$ dependent variables.

\subsection{Choose the Independent Variables}

In order to fully reflect the ten principles of urban smart growth and a city's geographical conditions, growth needs and other aspects, we select ten indicators as below:

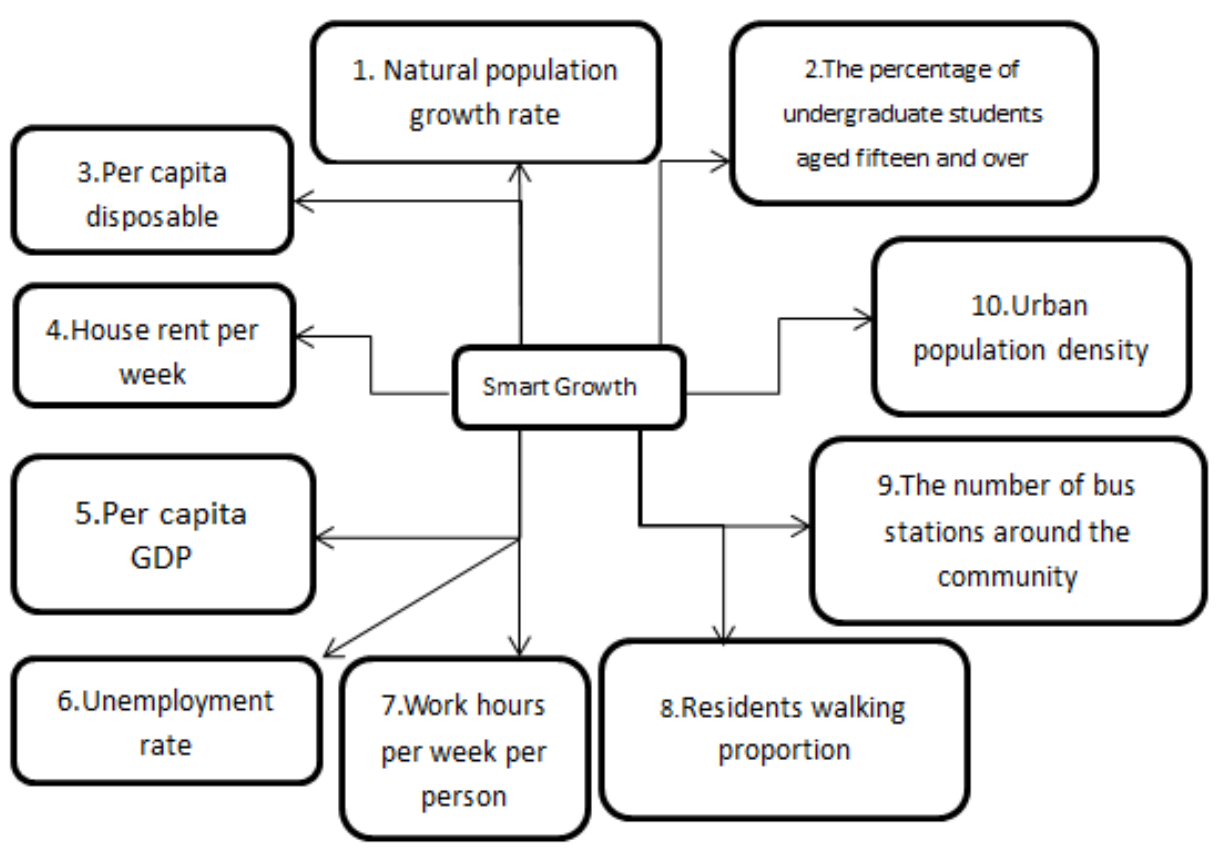

Figure 2: Ten indicators we will consider.

By using Principal Component Analysis[4][5], we draw the conclusion that natural population growth rate, the percentage of people with a college diploma aged fifteen and over, per capita disposable income, per capita GDP, unemployment rate, and the number of bus stations around the community have a greater impact on the urban smart growth.

In each country, natural population growth rate, per capita disposable income, per capita GDP must be considered during the development. So, they belongs to independent variables. 
In Bendigo, considering the present situation, the percentage of people with a college diploma aged fifteen and over is low, besides, Bendigo is an inland city which means developing public transportation is essential necessary. So we design smart growth plans for natural population growth rate, per capita disposable income, per capita GDP, the percentage of people with a college diploma aged fifteen and over and the number of bus stations around the community.

In Galway, because of European economy downturn, unemployment rate is high, the government should design plans to control unemployment rate. So we design smart growth plans for natural population growth rate, per capita disposable income, per capita GDP and unemployment rate.

According to the chosen cities' data in recent years [6] [7], we draft smart growth plans as follow: Table 1: The excepted value of the selected indicators after 20 years.

\begin{tabular}{c|c|c|c|c|c|c}
\hline \hline & $1(\%)$ & $2(\%)$ & $3(€)$ & $5(€)$ & $6(\%)$ & 9 \\
\hline Bendigo & 1.95 & 22.6 & 31000 & 7.1 & ---- & 3.5 \\
\hline Galway & 1.34 & ---- & 29000 & 6.9 & 7.8 & ---- \\
\hline \hline
\end{tabular}

\subsection{Training Network and Calculate}

\subsubsection{Training Network [8]}

We use MATLAB neural network toolbox to set up a three-layer neural network and choose 6 cities' data in Australia and Ireland separately to train the neural network. The data in Bendigo and Galway are as test data. We find that the network training results is good when hidden layer nodes numbers are 6 and 7. ( Urban population density is not considered as input or output of neural network, the growth speed of urban population density is a little lower than that of natural population growth rate) Predicted output and expected output are as follow:

Table 2: Comparison of predicted value and expected value of BP neural network

\begin{tabular}{|c|c|c|c|c|c|c|c|}
\hline & & $2(\%)$ & $4(€)$ & $6(\%)$ & $7(€)$ & 8 & 9 \\
\hline \multirow{2}{*}{ Bendigo } & $\begin{array}{c}\text { Predicted } \\
\text { output }\end{array}$ & ---- & 316.2 & 5.53 & 37.6 & 50.4 & ---- \\
\hline & $\begin{array}{c}\text { Expected } \\
\text { output }\end{array}$ & ---- & 324.8 & 5.7 & 38 & 48.7 & ---- \\
\hline \multirow{2}{*}{ Galway } & $\begin{array}{c}\text { Predicted } \\
\text { output }\end{array}$ & 21.4 & 320.5 & ---- & 35.0 & 41.3 & 1.92 \\
\hline & $\begin{array}{c}\text { Expected } \\
\text { output }\end{array}$ & 20.5 & 303.2 & ---- & 37.0 & 42.6 & 2 \\
\hline
\end{tabular}

\subsubsection{Use Smart Growth Plans to Estimate Other Data}

We put smart growth plans' data into the neural network and get the other indicators for the next 20 years.

Table 3: The comparison of current value and predicted value after 20 years (unselected indicators).

\begin{tabular}{c|c|c|c|c|c|c|c|c}
\hline \hline \multicolumn{2}{c|}{} & $2(\%)$ & $4(€)$ & $6(\%)$ & $7(€)$ & 8 & 9 & 10 \\
\hline \multirow{3}{*}{ Bendigo } & Now & ---- & 324.8 & 5.70 & 38 & 48.7 & ---- & 33.3 \\
\cline { 2 - 9 } & $\begin{array}{c}20 \text { years } \\
\text { later }\end{array}$ & ---- & 498 & 5.45 & 38.2 & 50 & ----- & 45.2 \\
\hline \multirow{2}{*}{ Galway } & Now & 20.5 & 303.2 & ---- & 37 & 42.6 & 2 & 40.7 \\
\cline { 2 - 9 } & $\begin{array}{c}20 \text { years } \\
\text { later }\end{array}$ & 21.2 & 473 & ----- & 33.8 & 41.6 & 2.7 & 50.5 \\
\hline \hline
\end{tabular}

According to the results, the house rent will increase substantially while the other indicators are no significant changes in the next 20 years. 


\section{Conclusion}

We use the Principal Component Analysis to evaluate the indicators and find that after implementing our plan, the level of urban smart growth in Bendigo and Galway upgraded. We think our smart growth plan is successful.

In order to achieve our smart growth plan, we offer the following suggestions:

1. In terms of population, the two cities should encourage people to give birth to children, and provide subsidies to families with children.

2. In the economy, to provide more employment opportunities, encourage entrepreneurship, and control the price level.

3. In terms of urban development, they should increase the input of public transportation construction, expand the city rationally and pay more attention to the construction of urban culture.

By using Principal Component Analysis, We take the main components of the ten indicators and reduce the workload of data processing, eliminates the mutual influences among each index, so that we can avoid repeating calculation of the relevant of factors in data processing .At the same time, BP neural network realizes the mapping function from input to output ,solving the problem of complex relationship of input and output .And it has self-learning ability that it can extracted the reasonable rules automatically according to the given data.

While, for we just consider the finite factors, it is inevitable that the results cannot reflect that actual situation completely. When explaining the meaning of the principal component, it is ambiguous generally, not as clear as the original variable.it is unavoidable in the process of reducing the variable dimension. The possibility of the failure of network training exits. When it happens, we should repeat adjust the parameters. The data used for network training is not so much, therefore there is probably a small deviation between the predicted value and the expected value.

The success rate of urban smart growth is affected by many factors. There are also significant differences in the factors between different cities. Our model only considers the factors that have a greater impact on the two cities. To help implement the smart growth theories into city design around the world, we still have a long way to go.

\section{References}

[1]. From Urban Sprawl to Smart Growth, the Change of Land Use in America. Ma ZuQi.Urban Problems.2007 (10):86-90.

[2]. Ian Colquhoun. Building Sustainable Communities. Taiwan: SHU-TE University, 2005.

[3]. Feng Shi.Neural Network Analysis of 30 Cases.China.2009

[4]. Haiming Lin.An Analysis of Ten Problems in the Application of Principal Component Analysis. Statistics and Decision, 2007.8:16-18.

[5]. Liuping Sun, Wuyong Qian. Improvement of Comprehensive Evaluation Method Based on Principal Component Analysis. Mathematics in Practice and Theory, 2009(18):15-20.

[6]. http://www.cso.ie/en/index.html

[7]. http://www.abs.gov.au/browse?opendocument\&ref=topBar

[8]. SiShoukui, SunXijing. Mathematical Modeling,2011 